\title{
Angiología
}

www. elsevier. es/ angiologia

ORIGINAL

\section{Tratamiento quirúrgico del síndrome de atrapamiento de arteria poplítea: nuestra experiencia}

\section{B. Merino Díaz*, R. Salvador Calvo, A. Revilla Calavia, L. Carpintero Mediavilla, J.A. González Fajardo y C. Vaquero Puerta}

Servicio de Angiología y Cirugía Vascular, Hospital Clínico Universitario de Valladolid, Valladolid, España

Recibido el 7 de julio de 2010; aceptado el 10 de noviembre de 2010

\author{
PALABRAS CLAVE \\ Arteria poplítea; \\ Síndrome de \\ atrapamiento; \\ Diagnóstico; \\ Cirugía; \\ Tratamiento
}

\begin{abstract}
Resumen
Introducción: El síndrome de atrapamiento de la arteria poplítea (SAAP) es una entidad poco frecuente cuya incidencia varía del 0,17 al 3,5\%

Objetivo: Revisamos a los pacientes tratados quirúrgicamente en nuestro servicio durante los últimos 15 años.

Material y métodos: Estudio retrospectivo entre 1995 y 2009, en que se registraron variables demográficas, comorbilidad, clínica, exploración física, pruebas complementarias, tratamiento quirúrgico realizado, así como evolución a los 15 años.

Resultados: Se intervino quirúrgicamente a 8 pacientes (el $50 \%$ varones) por SAAP con una mediana de edad de 41,5 (intervalo, 16-62) años; 2 pacientes (25\% presentaron claudicación invalidante, $5(62,5 \%$, dolor de reposo y en 1 caso $(12,5 \%)$, lesiones tróficas. La prueba de elección en todos ellos fue la arteriografía, aunque también en 2 casos se realizó TC y en 3, angio-RM. El tratamiento quirúrgico fue miotomía con liberación de la arteria poplítea en 3 pacientes (37,5\%) (en uno de ellos se asoció injerto venoso), miotomía junto a trombectomía poplítea en 2 pacientes $(25 \%)$, bypass poplíteo-poplíteo con vena en otros $2(25 \%$ y un caso de simpatectomía lumbar (12,5\%). La arteriografía intraoperatoria fue normal. Durante el seguimiento a 15 años (mediana de seguimiento $7,5 \pm 3,98$ años) el $50 \%$ de los pacientes estaba asintomático, el $25 \%$ presentaba claudicación no invalidante y otro $25 \%$ falleció como consecuencia de su afección concomitante.

Conclusiones: En nuestra experiencia, la liberación de la arteria poplítea mediante miotomía del tendón de inserción anómalo, asociada o no a la realización de un bypass poplíteo-poplíteo, es el tratamiento quirúrgico de elección.
\end{abstract}

(c) 2010 SEACV. Publicado por Elsevier España, S. L. Todos los derechos reservados. \footnotetext{
2010).

Trabajo aceptado y presentado como póster en el 56 Congreso Nacional de la Sociedad Española de Angiología y Cirugía Vascular (junio,

*Autor para correspondencia.

Correo electrónico: borjamerino77@hotmail.com (B. Merino Díaz).
}

0003-3170/ \$ - see front matter @ 2010 SEACV. Publicado por Elsevier España, S. L. Todos los derechos reservados. 


\section{KEYWORDS}

Popliteal artery;

Entrapment

syndrome;

Diagnosis;

Surgery;

Treatment

\section{Surgical treatment of popliteal artery entrapment syndrome: our experience}

\begin{abstract}
Introduction: Popliteal artery entrapment syndrome (PAES) is a rare condition with an incidence that varies from $0.17-3.5 \%$

Aim: We reviewed patients treated with surgery in our department over the past 15 years.

Material and methods: A retrospective study between 1995-2009 recorded demographic variables, comorbidity, physical examination, diagnostic tests, surgical treatment and outcome at 15 years.

Results: Eight patients (50\% male) were treated with surgery for PAES, with a mean age 41.5 years (range, 16-62). Two patients ( $25 \%$ had disabling claudication, $5(62.5 \%$ pain at rest, and in one case $(12,5 \%)$ trophic lesions. The test of choice in all of them was arteriography, although two patients also had a CT and three an angio-MR. Surgery was myotomy with release of the popliteal artery in three patients (37.5\%) (one of them involving vein graft), myotomy with popliteal thrombectomy in two patients $(25 \%)$, popliteal-popliteal bypass with vein in another $2(25 \%)$, and one case of lumbar sympathectomy (12.5\%). Intraoperative arteriography was normal in all cases. During follow-up to 15 years (mean $7.5 \pm 3.98$ years), $50 \%$ of patients were asymptomatic, $25 \%$ had no disabling claudication, and another $25 \%$ died as a result of disease.

Conclusions: In our experience, the release of the popliteal artery by myotomy abnormal tendon insertion, with or without conducting a popliteal-popliteal bypass, is the surgical treatment of choice.

(c) 2010 SEACV. Published by Elsevier España, S. L. All rights reserved.
\end{abstract}

\section{Introducción y objetivos}

El síndrome de atrapamiento de la arteria poplítea (SAAP) es una entidad clínica poco frecuente debido a una relación anómala entre esta arteria y las estructuras musculotendinosas circundantes, y constituye una importante causa de arteriopatía periférica no arteriosclerótica en pacientes jóvenes.

Fue Stuart ${ }^{1,2}$ quien, por primera vez, en 1879 describió la anomalía anatómica de la arteria poplítea en relación con el músculo gemelo interno al disecar la extremidad inferior amputada a un paciente de 64 años. Casi un siglo después, en 1965, Love y Whelan ${ }^{1,3}$ acuñaron el término de SAAP al describir la compresión que la inserción del tendón del gemelo interno o algún fascículo accesorio de este pueden producir sobre dicha arteria; de este modo se produce un cuadro clínico que conforma el citado síndrome.

La compresión crónica de la arteria poplítea genera lesión de la pared vascular y puede producir engrosamiento de la capa media, lesión intimal, trombosis y formación de aneurismas, lo que puede llevar a la amputación de la extremidad por gangrena. Por todo ello, el diagnóstico y tratamiento oportunos son de gran importancia para el paciente $e^{4}$.

EI SAAP presenta cinco variedades anatómicas principales, tal y como establece la clasificación de Insua-Rich ${ }^{1,5}$ (fig. 1):

1. El tipo I corresponde al desplazamiento medial de la arteria, producido por la inserción del gemelo interno.

2. El tipo II es similar al anterior, pero con un menor desplazamiento de la arteria, ya que en este caso la inserción del gemelo interno es anómala y se produce más externamente.
3. En el tipo III la arteria se comprime por una banda muscular accesoria del músculo gemelo interno.

4. En el tipo IV es el músculo poplíteo profundo o una banda fibrosa que sigue a dicho músculo, la que atrapa a la arteria.

5. El tipo $\mathrm{V}$ incluye cualquiera de las anteriores y acompaña el atrapamiento de la vena poplítea.

En las últimas revisiones de la clasificación del SAAP se describe un sexto tipo que es el síndrome de atrapamiento de la arteria poplítea funcional ${ }^{5,6}$, consistente en la compresión extrínseca de la arteria poplítea sin que se identifiquen alteraciones anatómicas, ocasionada por hipertrofia muscular, que es de tipo funcional.

El objetivo de este estudio es mostrar nuestra experiencia en el manejo diagnóstico y el tratamiento quirúrgico de este síndrome durante los últimos 15 años en nuestro servicio.

\section{Pacientes y metodología}

Se diseñó un estudio descriptivo-retrospectivo con el fin de revisar a los pacientes tratados quirúrgicamente de SAAP en nuestro servicio desde 1995 hasta 2009. Se registraron las siguientes variables demográficas y clínicas: datos de filiación, edad, sexo, comorbilidad, forma de presentación (aguda o crónica), así como clínica al diagnóstico.

Asimismo, registramos datos referentes a la exploración física vascular (presencia de pulsos e índice tobillo-brazo en extremidades inferiores), pruebas complementarias diagnósticas realizadas (arteriografía, tomografía computarizada [TC] o resonancia magnética [RM]), necesidad o no de tratamiento médico inicial antes de la cirugía y procedimiento quirúrgico empleado con el resultado inmediato obtenido. 
Tipo I
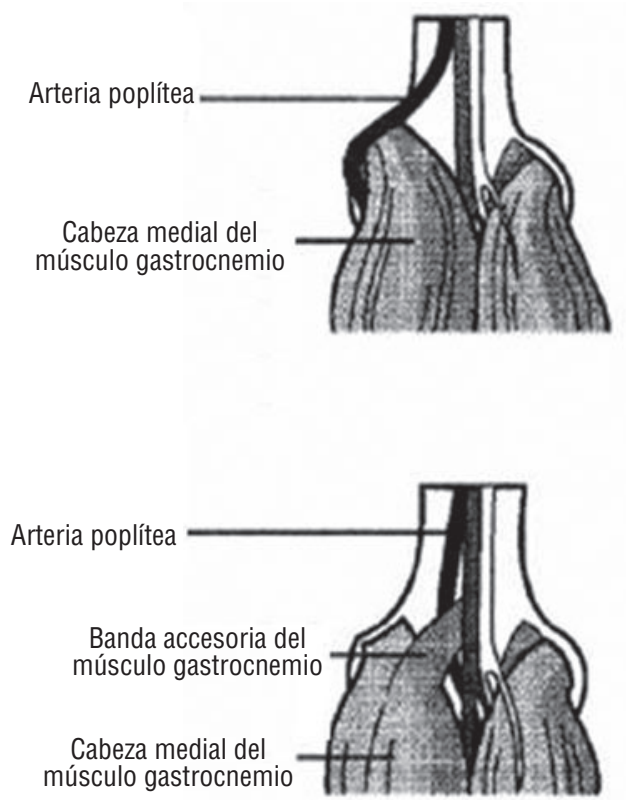

Tipo III
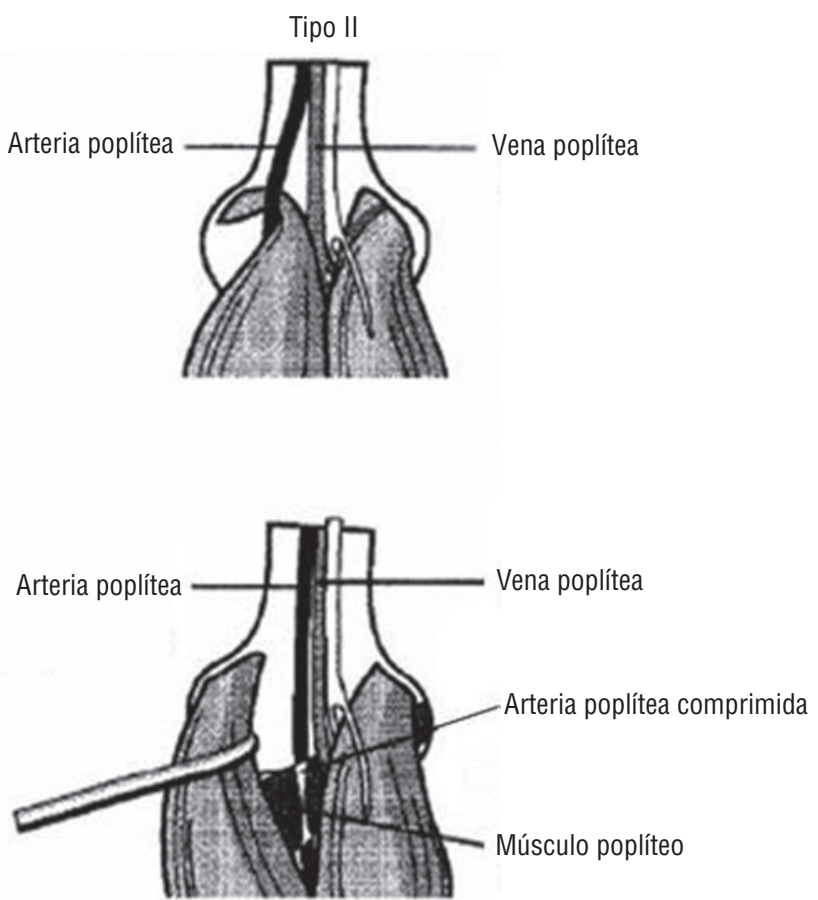

Tipo IV

Figura 1 Tipos de atrapamiento poplíteo (clasificación de Insua-Rich).

Además, se recogieron datos del seguimiento realizado desde su intervención quirúrgica hasta el momento actual a los pacientes tratados, tales como anamnesis y valoración clínica con determinación de pulsos e índice tobillo-brazo en extremidades inferiores, así como realización de eco-doppler para valorar la permeabilidad poplítea y/ o de los bypass realizados. Se consideró "momento actual" a la situación clínica y exploración física vascular que presentaron los pacientes en la última revisión realizada en marzo de 2010.

\section{Resultados}

Durante el periodo 1995-2009, se trató quirúrgicamente en nuestro servicio a 3.419 pacientes por arteriopatía periférica. De todos ellos, se intervino quirúrgicamente por SAAP a 8 pacientes (el $50 \%$ varones), con una mediana de edad de 41,5 (intervalo, 16-62) años; 4 pacientes (50\%) eran fumadores, y 2 de ellos tenían antecedentes de insuficiencia cardíaca y dislipemia ( $25 \%$ ). El resto (50\%) no presentó antecedentes médicos ni hábitos tóxicos de interés.

En cuanto a la forma de instauración de los síntomas, $6 \operatorname{casos}(75 \%)$ se iniciaron de forma aguda, mientras que en un $25 \%$ los pacientes referían clínica de larga evolución. En la tabla 1 figuran las principales variables y resultados recogidos para cada paciente.

La clínica que presentaron al diagnóstico fue la siguiente: 2 pacientes ( $25 \%$ presentaron claudicación invalidante; 5 $(62,5 \%)$, dolor de reposo, y en 1 caso $(12,5 \%$, lesiones tróficas y dolor de reposo asociado. En cuanto a la exploración física, podemos decir que el pulso poplíteo y los distales estaban abolidos en la extremidad afecta en todos los casos (en dos pacientes, tales pulsos estaban ausentes con la flexión de la rodilla y la dorsoflexión y flexión plantar). La prueba de elección en todos ellos fue la arteriografía, aunque en 2 casos se realizó además angio-TC y en 3, angio-RM (fig. 2), en relación con el avance en los últimos años de las

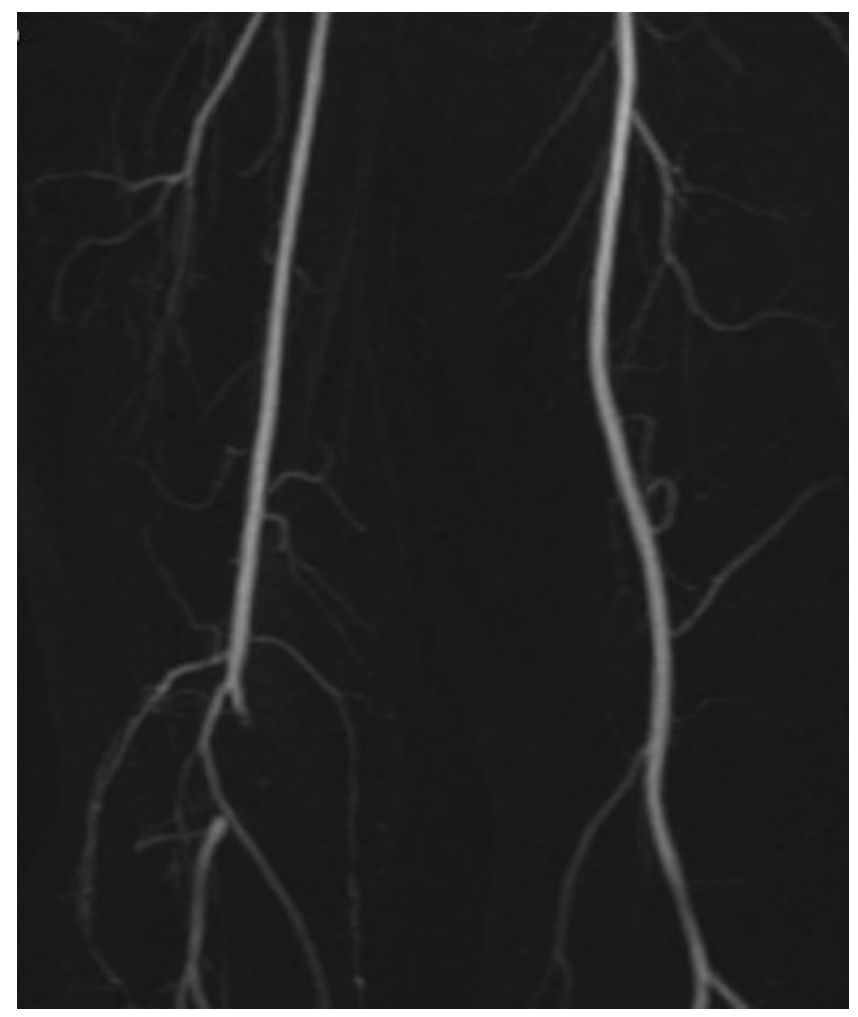

Figura 2 Resonancia magnética que muestra atrapamiento poplíteo derecho. 
Tabla 1 Principales variables recogidas sobre cada uno de los pacientes

\begin{tabular}{|c|c|c|c|c|c|c|c|c|c|}
\hline $\begin{array}{c}\text { Paciente, } \\
n . \stackrel{0}{ }\end{array}$ & Sexo & Edad & Presentación & $\begin{array}{l}\text { Síntomas } \\
\text { clínicos }\end{array}$ & $\begin{array}{l}\text { Pulsos, } \\
\text { derecha }\end{array}$ & $\begin{array}{l}\text { Pulsos, } \\
\text { izquierda }\end{array}$ & $\begin{array}{c}\text { YAO, } \\
\text { derecho }\end{array}$ & $\begin{array}{c}\text { YAO, } \\
\text { izquierdo }\end{array}$ & Angiografía \\
\hline 1 & Mujer & 42 & Aguda & $\begin{array}{l}\text { Dolor de } \\
\text { reposo } \\
\text { izquierdo }\end{array}$ & Distales & $\begin{array}{l}\text { Femoral } \\
\text { (con } \\
\text { flexión } \\
\text { plantar) }\end{array}$ & 1 & $\begin{array}{l}0,65 \\
\text { flexión } \\
\text { plantar }\end{array}$ & $\begin{array}{l}\text { Desplazamiento } \\
\text { arteria poplítea } \\
\text { izquierda }\end{array}$ \\
\hline 2 & Mujer & 41 & Aguda & $\begin{array}{l}\text { Dolor de } \\
\text { reposo } \\
\text { derecho }\end{array}$ & Femoral & Distales & 0,72 & 1 & $\begin{array}{l}\text { Oclusión arteria } \\
\text { poplítea derecha } \\
\text { y recanalización } \\
\text { infragenicular }\end{array}$ \\
\hline 3 & Mujer & 16 & Aguda & $\begin{array}{l}\text { Claudicación } \\
\text { invalidante } \\
\text { izquierda }\end{array}$ & Distales & Femoral & 1 & 0,73 & $\begin{array}{l}\text { Oclusión arteria } \\
\text { poplítea izquierda } \\
\text { y recanalización } \\
\text { infragenicular }\end{array}$ \\
\hline 4 & Varón & 32 & Crónica & $\begin{array}{l}\text { Dolor de } \\
\text { reposo } \\
\text { y lesiones } \\
\text { tróficas } \\
\text { izquierdas }\end{array}$ & Distales & Femoral & 1 & 0,3 & $\begin{array}{c}\text { Trombosis de tercera } \\
\text { porción de poplítea } \\
\text { con salida a tibial } \\
\text { anterior izquierda }\end{array}$ \\
\hline 5 & Varón & 51 & Aguda & $\begin{array}{l}\text { Dolor de } \\
\text { reposo } \\
\text { derecho }\end{array}$ & $\begin{array}{l}\text { Femoral } \\
\text { (con } \\
\text { flexión } \\
\text { plantar) }\end{array}$ & Distales & $\begin{array}{l}0,68, \\
\text { flexión } \\
\text { plantar }\end{array}$ & 1 & $\begin{array}{l}\text { Desplazamiento } \\
\text { arteria poplítea } \\
\text { derecha }\end{array}$ \\
\hline 6 & Varón & 21 & Crónica & $\begin{array}{l}\text { Claudicación } \\
\text { invalidante } \\
\text { derecha }\end{array}$ & Femoral & Distales & 0,75 & 1 & $\begin{array}{l}\text { Trombosis de primera } \\
\text { porción de poplítea } \\
\text { que recanaliza a } \\
\text { tercera porción con } \\
\text { salida a } 3 \text { troncos } \\
\text { distales }\end{array}$ \\
\hline 7 & Varón & 47 & Aguda & $\begin{array}{l}\text { Dolor y } \\
\text { frialdad } \\
\text { derecha }\end{array}$ & Femoral & Distales & 0 & 1 & $\begin{array}{l}\text { Compresión de } \\
\text { segunda porción } \\
\text { poplítea }\end{array}$ \\
\hline 8 & Mujer & 62 & Aguda & $\begin{array}{l}\text { Dolor y } \\
\text { frialdad } \\
\text { izquierda }\end{array}$ & Distales & Femoral & 1 & 0 & $\begin{array}{l}\text { Trombosis poplítea } \\
\text { izquierda por } \\
\text { compresión de } \\
\text { bandas fibrosas } \\
\text { musculares }\end{array}$ \\
\hline
\end{tabular}

técnicas de imagen. En 3 casos (37,5\%) el SAAP era un tipo III de la clasificación de Insua-Rich, tipo II en otros 3 casos $(37,5 \%)$, tipo I en 1 caso $(12,5 \%)$ y tipo IV en otro caso $(12,5 \%$ ). Ningún paciente presentó afectación bilateral. Asimismo, no se registró ningún caso de aneurisma poplíteo.

Sólo 2 pacientes ( $25 \%$ recibieron tratamiento médico inicial con pentoxifilina como opción terapéutica previa a la cirugía debido a la ausencia de dolor de reposo en el momento diagnóstico (presentaban claudicación invalidante) y porque inicialmente habían rechazado la intervención quirúrgica. Se realizaron 5 abordajes anatómicos (62,5\%) y 2 extraanatómi$\cos (25 \%$. Así, el tratamiento quirúrgico consistió en miotomía con liberación de la arteria poplítea en 3 pacientes $(37,5 \%$ ) (en uno de ellos se asoció injerto venoso) (fig. 3), miotomía junto a trombectomía poplítea en 2 pacientes ( $25 \%$ ), bypass poplíteo-poplíteo con vena en otros $2(25 \%)$ y un caso de simpatectomía lumbar (12,5\%) de hacía 15 años que presentaba arteriopatía distal asociada al SAAP. 


\begin{tabular}{|c|c|c|c|c|c|c|}
\hline TC & RM & Tipo & $\begin{array}{c}\text { Tratamiento } \\
\text { quirúrgico }\end{array}$ & $\begin{array}{c}\text { Resultado } \\
\text { al alta }\end{array}$ & Seguimiento & Estado actual \\
\hline No & No & I & $\begin{array}{l}\text { Miotomía de tendón } \\
\text { de inserción anómalo } \\
\text { con liberación de } \\
\text { arteria poplítea }\end{array}$ & $\begin{array}{l}\text { Satisfactoria. } \\
\text { Pulsos distales } \\
\text { YAO izquierdo, } \\
1\end{array}$ & 5 años & $\begin{array}{l}\text { Asintomático. Pulsos } \\
\text { distales YAO } \\
\text { izquierdo, } 1 . \\
\text { Permeabilidad } \\
\text { poplítea }\end{array}$ \\
\hline No & $\begin{array}{l}\text { Atrapamiento de } \\
\text { arteria poplítea } \\
\text { derecha por } \\
\text { inserción del } \\
\text { tendón del gemelo } \\
\text { interno }\end{array}$ & II & $\begin{array}{l}\text { Bypass poplíteo-poplíteo } \\
\text { con vena safena } \\
\text { interna }\end{array}$ & $\begin{array}{l}\text { Satisfactoria. } \\
\text { YAO derecho, } \\
0,88\end{array}$ & 10 años & $\begin{array}{l}\text { Asintomático. } \\
\text { YAO derecho, } 0,9 . \\
\text { Bypass permeable }\end{array}$ \\
\hline $\begin{array}{l}\text { Inclusión de } \\
\text { arteria } \\
\text { poplítea } \\
\text { izquierda en } \\
\text { gemelo }\end{array}$ & No & II & $\begin{array}{l}\text { Miotomía de tendón } \\
\text { de inserción } \\
\text { anómalo con liberación } \\
\text { de arteria } \\
\text { poplítea + injerto } \\
\text { venoso término- } \\
\text { terminal de vena } \\
\text { safena interna }\end{array}$ & $\begin{array}{l}\text { Satisfactoria. } \\
\text { Pulsos distales } \\
\text { YAO izquierdo, } \\
1\end{array}$ & 10 años & $\begin{array}{l}\text { Asintomático. } \\
\text { Pul sos distales } \\
\text { YAO izquierdo, } 1 . \\
\text { Injerto venoso } \\
\text { permeable }\end{array}$ \\
\hline $\begin{array}{l}\text { Haz aberrante } \\
\text { muscular } \\
\text { compatible } \\
\text { con } \\
\text { atrapamiento } \\
\text { poplíteo } \\
\text { izquierdo }\end{array}$ & No & III & $\begin{array}{l}\text { Simpatectomía lumbar } \\
\text { izquierda } \\
\text { extraperitoneal }\end{array}$ & $\begin{array}{l}\text { Desaparece dolor } \\
\text { de reposo } \\
\text { y secan } \\
\text { lesiones. YAO } \\
\text { izquierdo, 0,45 }\end{array}$ & 5 años & $\begin{array}{l}\text { Fallecimiento } \\
\text { (5 años) }\end{array}$ \\
\hline No & No & III & $\begin{array}{l}\text { Miotomía de tendón de } \\
\text { inserción anómalo con } \\
\text { liberación de arteria } \\
\text { poplítea }\end{array}$ & $\begin{array}{l}\text { Satisfactoria. } \\
\text { Pulsos distales } \\
\text { YAO derecho, } 1\end{array}$ & 5 años & $\begin{array}{l}\text { Asintomático. } \\
\text { YAO derecho, 0, } 6 \text {. } \\
\text { Permeabilidad } \\
\text { poplítea }\end{array}$ \\
\hline No & $\begin{array}{l}\text { Atrapamiento de } \\
\text { arteria poplítea } \\
\text { derecha por } \\
\text { inserción del } \\
\text { tendón del gemelo } \\
\text { interno }\end{array}$ & II & $\begin{array}{l}\text { Bypass poplíteo-poplíteo } \\
\text { con vena safena } \\
\text { interna invertida }\end{array}$ & $\begin{array}{l}\text { Satisfactorio } \\
\text { YAO derecho, } \\
0,93\end{array}$ & 4 años & $\begin{array}{l}\text { Trombosis bypass } \\
\text { poplíteo-poplíteo. } \\
\text { Compensado } \\
\text { clínicamente } \\
\text { (YAO derecho, } \\
0,68)\end{array}$ \\
\hline No & No & IV & $\begin{array}{l}\text { Trombectomía y sección } \\
\text { de fibras musculares } \\
\text { con liberación de } \\
\text { arteria poplítea }\end{array}$ & $\begin{array}{l}\text { Satisfactoria. } \\
\text { YAO derecho, } \\
0,78\end{array}$ & 15 años & $\begin{array}{l}\text { Claudicación a } 200 \mathrm{~m} \\
\text { (YAO derecho, } \\
\text { 0,43). Oclusión } \\
\text { poplítea }\end{array}$ \\
\hline No & $\begin{array}{l}\text { Haz aberrante } \\
\text { muscular } \\
\text { compatible con } \\
\text { atrapamiento } \\
\text { poplíteo izquierdo }\end{array}$ & III & $\begin{array}{l}\text { Trombectomía y sección } \\
\text { de fibras musculares } \\
\text { con liberación de } \\
\text { arteria poplítea }\end{array}$ & $\begin{array}{l}\text { Satisfactoria. } \\
\text { Pulsos distales, } \\
\text { YAO izquierdo, } \\
1\end{array}$ & 10 años & $\begin{array}{l}\text { Fallecimiento } \\
\qquad(10 \text { años) }\end{array}$ \\
\hline
\end{tabular}

La arteriografía intraoperatoria fue normal en todos los casos en que se realizó abordaje anatómico o extraanatómi$\mathrm{co}$, con resultado posquirúrgico inmediato satisfactorio. En el caso de la simpatectomía lumbar, el éxito técnico fue comprobado mediante el incremento de la temperatura en la extremidad inferior intervenida. Todo ello se traduce en una tasa de permeabilidad primaria del $100 \%$ de los pacientes sometidos a cirugía de revascularización. Asimismo, no se registró mortalidad intraoperatoria ni perioperatoria.
Al alta, los pacientes recibieron tratamiento con ácido acetilsalicílico $100 \mathrm{mg} /$ día.

Durante su evolución (mediana de seguimiento 7,5 \pm 3,98 años), 4 pacientes ( $50 \%$ ) estaban asintomáticos, $2(25 \%)$ fallecieron como consecuencia de su enfermedad concomitante, 1 paciente (12,5\%) presentaba claudicación intermitente a $200 \mathrm{~m}$, con índice tobillo-brazo de 0,43, y otro paciente $(12,5 \%$ presentó trombosis del bypass poplíteo-poplíteo con permeabilidad de ramas geniculares, com- 


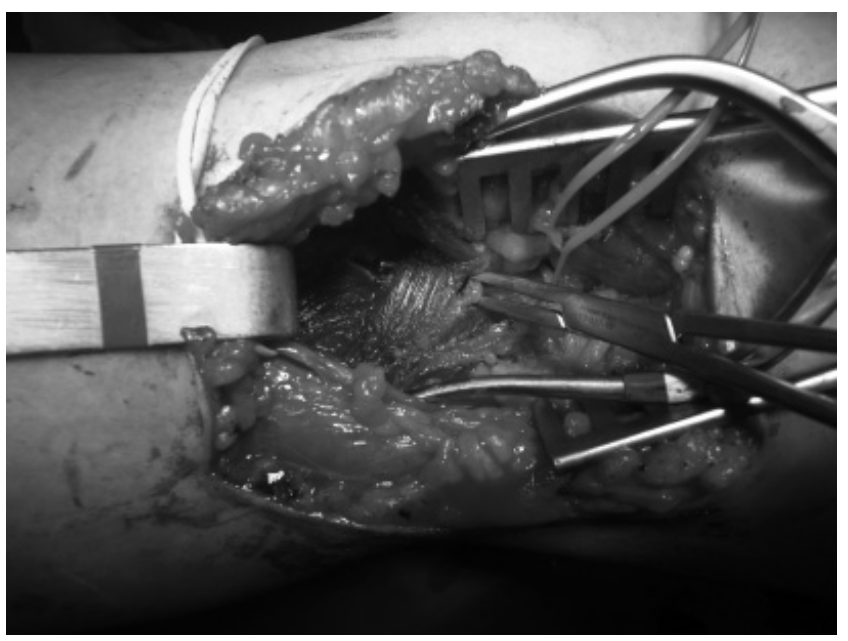

Figura 3 Miotomía de tendón aberrante.

pensado clínicamente, y con índice tobillo-brazo de 0,68. Ello se traduce en una tasa de reoclusiones del $25 \%$ Por lo demás, no fue necesaria la reintervención quirúrgica por complicaciones postoperatorias en ninguno de los pacientes durante los 15 años de seguimiento.

\section{Discusión}

EI SAAP es una entidad poco frecuente cuya incidencia varía entre un 0,17 y un 3,5\% según las series publicadas ${ }^{7,8}$. Así, Gibson ${ }^{6}$ llega a estas cifras tras un estudio en cadáveres de 20.000 soldados griegos asintomáticos; además, concluye que sólo una pequeña proporción de casos da lugar a síntomas. Por otro lado, el atrapamiento concomitante de la vena poplítea con la arteria se ha publicado en sólo el 7,6\% de los $\operatorname{casos}^{9,10}$. En nuestra serie, la incidencia del SAAP tratado quirúrgicamente se sitúa en torno al 0,23\% de los pacientes tratados quirúrgicamente por arteriopatía periférica.

Está producido por una anomalía congénita del músculo o del tendón de inserción en relación con la arteria poplítea que causa su oclusión y trombosis; aunque cada vez se han descrito más casos de una forma de atrapamiento poplíteo de tipo funcional (oclusión temporal y postural de la arteria) debido a la compresión extrínseca de la arteria poplítea producida por la hipertrofia muscular sin evidenciarse alteraciones anatómicas ${ }^{6,11}$.

Es frecuente su aparición en gente joven y debe tenerse en cuenta su diagnóstico cuando se trate de un paciente joven con claudicación intermitente de etiología no arteriosclerótica. Esta anomalía afecta generalmente a varones jóvenes de 20 a 40 años; es la afección más frecuente entre las entidades clínicas que causan claudicación intermitente en pacientes jóvenes ${ }^{12}$. En nuestra serie, no hubo diferencias entre sexos, pero la media de edad se situó en los intervalos publicados en la literatura.

La forma clínica de presentación del SAAP es de claudicación intermitente en el $69 \%$ de los casos, y constituye la manifestación de isquemia aguda en el $26 \%$ esta última forma de presentación se acompaña de un alto porcentaje de complicaciones (síndrome compartimental, fundamental- mente) y amputaciones 5 . Sin embargo, en nuestra experiencia, predominó la forma de instauración clínica aguda con dolor, palidez y frialdad de la extremidad afecta en un $62,5 \%$ de los casos, quizá por un fallo en el diagnóstico en estadios más precoces.

El diagnóstico debe basarse en una correcta anamnesis, exploración física vascular con determinación de pulsos e índice tobillo-brazo en extremidades inferiores, así como pruebas complementarias. Los pulsos deben explorarse con la articulación del pie y la rodilla en flexión y en extensión, con el fin de resaltar la compresión arterial del gemelo. Así, ante la dorsoflexión pasiva del pie, el flujo arterial disminuirá y con él la amplitud de pulso tibial posterior y pedio. Por otra parte, en la extensión forzada de la rodilla el pulso tiende a desaparecer. Sin embargo, estas maniobras no son específicas y se ha observado que en personas normales estas pruebas también pueden ser positivas ${ }^{13}$

En cuanto a las pruebas de imagen, se ha experimentado una notable evolución en los últimos 15 años en cuanto a sus indicaciones desde el eco-Doppler, la angiografía, la TC y la RM. En efecto, las imágenes de RM son cada vez más reconocidas como las que mejor prueban la relación anormal entre la arteria poplítea y las estructuras musculotendinosas circundantes ${ }^{14-16}$. Esta técnica ha demostrado ser superior al eco-doppler y la TC, ya que obtiene resultados similares a los de la arteriografía con sustracción digital para definir la alteración en el SAAP. Además, las imágenes de RM son útiles cuando la arteria poplítea está ocluida, situación en la que el eco-Doppler y la angiografía tienen un valor limitado ${ }^{15,16}$. Por todo ello, la RM es la técnica diagnóstica de imagen ideal como método de cribado en el SAAP ${ }^{16-18}$.

El tratamiento quirúrgico podrá ser anatómico o extraanatómico. Cuando la revascularización es anatómica (paciente en decúbito prono con abordaje poplíteo posterior mediante incisión en forma de S), no sólo será necesaria la reparación vascular mediante injerto o plastia venosa, sino que también es obligada la sección de la estructura musculotendinosa que causa la compresión arterial. En casos en que se opte por un abordaje extraanatómico mediante un bypass con vena tunelizado por la cara interna de la pierna, no será necesaria la corrección quirúrgica muscular 13,19,20. La opción de un abordaje u otro dependerá de la integridad y permeabilidad de la arteria poplítea en el momento del diagnóstico.

Así, cuando este se haya realizado precozmente y la arteria poplítea no esté afectada, el tratamiento de elección será la liberación de la arteria poplítea con la sección de las estructuras musculotendinosas aberrantes ${ }^{12,21}$. Si el diagnóstico se realiza en una fase más tardía, en la que la arteria poplítea se halla ocluida o estenosada, el tratamiento de elección consistirá en la reparación vascular, además de la sección de la estructura musculotendinosa causante de la compresión arterial. En los casos en que la permeabilidad de la arteria poplítea no pueda ser garantizada mediante la sección del tendón aberrante, la revascularización mediante injerto venoso será la técnica de elección, mediante la realización de un bypass poplíteo-poplíteo (como sucedió en 2 de nuestros casos) tan corto como sea posible; el material de elección es la vena safena interna; también se puede emplear la vena safena externa, si es de buena calidad, que es muy accesible en un abordaje posterior ${ }^{12}$. 
En el SAAP, el tratamiento endovascular no ha demostrado eficacia. Por ello, está contraindicada la recanalización mediante angioplastia y stent, por la compresión extrínseca, la movilización en la interlínea articular y los malos resultados en este sector ${ }^{22-25}$.

En conclusión, podemos decir que el SAAP es una causa infrecuente pero importante de isquemia arterial en pacientes jóvenes, que debe incluirse en el diagnóstico diferencial ante la oclusión aguda de la arteria poplítea, claudicación o dolores atípicos en pacientes jóvenes, especialmente varones. El diagnóstico precoz y minucioso, así como un adecuado tratamiento, influye en la recuperación ad integrum del paciente. La resección del tendón aberrante, de forma aislada o asociando injerto venoso, para reestablecer la normalidad anatómica de la fosa poplítea, es el tratamiento quirúrgico de elección.

\section{Conflicto de intereses}

Los autores declaran no tener ningún conflicto de intereses.

\section{Bibliografía}

1. Delgado R, Moga LL, Muncunill J, Mañosa J. Síndrome de atrapamiento de arteria poplítea en tres jóvenes deportistas. Angiología. 1993; 45:99-102.

2. Stuart TPA. Note on variation in the course of popliteal artery. J Anat Physiol. 1879; 13:162-5.

3. Love J, Whelan TJ . Popliteal artery entrapment syndrome. Am J Surg. 1965;109:620-4.

4. Sookur PA, Naraghi AM, Bleakney RR, Jalan R, Chan O, White LM. Accesory muscles: anatomy, symptoms, and radiologic evaluation. Radiographics. 2008;28:481-99.

5. Villalba V, García R, Cisneros I. Aneurisma de la arteria poplítea como complicación del síndrome de atrapamiento de la arteria poplítea. Angiología. 2003;55:450-4.

6. Noorani A, Walsh SR, Cooper DG, Varty K. Entrapment syndromes. Eur J Vasc Endovasc Surg. 2009;37:213-20.

7. Bouhoutsos J, Daskalakis E. Muscular abnormalities affecting the popliteal vessels. Br J Surg. 1981;68:501-6.

8. Gibson MHL, Mills JG, Johnson GE, Downs AR. Popliteal entrapment syndrome. Ann Surg. 1977; 185:341-8.

9. Persky JM, Kempezinski RF, Fowl RJ. Entrapment of the popliteal artery. Surg Gynecol Obstet. 1991;173:84-90.
10. Gourgiotis S, Aggelakas J, Salemis N, Elias C. Diagnosis and surgical approach of popliteal artery entrapment syndrome: a retrospective study. Vascular Health and Risk Management. 2008; 4:83-8.

11. Causey MW, Singh N, Miller S, Quan R, Curry T, Andersen C. Intraoperative duplex and functional popliteal entrapment syndrome: strategy for effective treatment. Ann Vasc Surg. 2010;24:556-61.

12. Radonic V, Koplic S, Giunio L, Buca A. Popliteal artery entrapment syndrome. Diagnosis and management, with report of three cases. Tex Heart Ins J . 2000;27:3-13.

13. Pardo J M, Calpena R, Vázquez J L, Ventura E, Diego M, Díez M, et al. Síndrome de atrapamiento de arteria poplítea. Angiología. 1985; 37:255-61.

14. Baltopoulos P, Filippou D, Sigala F. Popliteal artery entrapment syndrome. Anatomic or functional syndrome? Clin J Sport Med. 2004; 14:8-12.

15. Lambert WA, Wilkins DC. Popliteal artery entrapment syndrome. Br J Surg. 1999; 86:1365-70.

16. Norese M, Ferreira $S$, Garrido S. Resonancia magnética en el atrapamiento poplíteo. Angiología. 2006; 58:509-10.

17. McGuinness G, Durham J D, Rutherford RB, Thickman D, Kumpe DA. Popliteal artery entrapment: findings at MR imaging. J Vasc Interv Radiol. 1991;2:241-5.

18. Papaioannou S, Tsitouridis K, Giataganas G. Evaluation of popliteal arteries with CT angiography in popliteal artery entrapment syndrome. Hippokratia. 2009;13:32-7.

19. Schurmann G, Mattfeldt T, Hofmann W. The popliteal artery entrapment syndrome: presentation, morphology and surgical treatment of 13 cases. Eur J Vasc Surg. 1990;4:223-31.

20. McAree BJ , O'Donnell ME, Davison GW, Boyd C, Lee B, Soong CV. Bilateral popliteal artery occlusion in a competitive bike rider: case report and clinical review. Vasc Endovascular Surg. 2008; 42:380-5.

21. Turnipseed WD. Popliteal entrapment syndrome. J Vasc Surg. 2002;35:910-5.

22. Levien LJ . Popliteal artery entrapment syndrome. Semin Vasc Surg. 2003; 16:223-31.

23. Bustabad M, Ysa A, Perez E, Merino J, Bardon F, Vela P. Popliteal artery entrapment: eight years experience. EJ VES Extra. 2006; 12:43-51.

24. Soobrah R, Nawaz A, Hussain T. Popliteal artery entrapment syndrome presenting with acute limb ischaemia: a case report. Case Report Med. 2010;2010:281925.

25. Di Marzo L, Cavallaro A, O'Donnell SD, Shigematsu H, Levien LJ , Rich NM. Endovascular stenting for popliteal vascular entrapment is not recommended. Ann Vasc Surg. En prensa 2010. 